\title{
Focus on Blunt Solid Organ Injuries
}

The management of patients with solid organ injuries has changed since the introduction of technically advanced imaging tools such as ultrasonography and multiple-scan computed tomography (CT), interventional radiological techniques and modern intensive care units. Almost two or three decades ago, many centers performed routine laparotomy in blunt abdominal trauma with signs of peritoneal irritation [1, 2]. The presence of blood following the application of diagnostic peritoneal lavage in blunt abdominal trauma frequently necessitated laparotomy in the past, and often concluded with nontherapeutic intervention.

In spite of this development in the management of these patients, major solid organ traumas can still be challenging. There has been great improvement in the nonoperative management (NOM) of intra-abdominal solid organ injury in recent decades. In most cases, treatment of injuries has shifted from early surgical treatment to NOM. NOM of blunt abdominal injuries is well established and strategies based on hemodynamic stability and CT scan findings are now widely used in the treatment of solid organ injuries [3-5].
Over the past three decades multiple studies have shown that NOM of solid organ injuries is effective, with a reported success rate of more than $90 \%$ [3-5].

\section{Korhan Taviloglu}

Section Editor

\section{References}

1. Knudson MM, Maull KI. Nonoperative management of solid organ injuries. Past, present, and future. Surg Clin North Am 1999;79:1357-71.

2. Pachter HL, Guth AA, Hofstetter SR, et al. Changing patterns in the management of splenic trauma: the impact of nonoperative management. Ann Surg 1998;227:708-17. discussion 717-9.

3. Malhotra AK, Fabian TC, Croce MA, et al. Blunt hepatic injury: a paradigm shift from operative to nonoperative management in the 1990s. Ann Surg 2000;231:804-13.

4. Yanar H, Ertekin C, Taviloglu K, et al. Nonoperative treatment of multiple intra-abdominal solid organ injury after blunt abdominal trauma. J Trauma 2008;64:943-8.

5. Myers GL, Dent DL, Stewart RM, et al. Blunt splenic injuries: dedicated trauma surgeons can achieve a high rate of nonoperative success in patients of all ages. J Trauma 2000;48:801-6. 